\title{
Evaluation of Visibility of Foreign Bodies in the Maxillofacial Region: Comparison of Computed Tomography, Cone Beam Computed Tomography, Ultrasound and Magnetic Resonance Imaging
}

\author{
Solmaz Valizadeh, ${ }^{1,2}$ Hamidreza Pouraliakbar, ${ }^{2}$ Leila Kiani, ${ }^{3}$ Yaser Safi, ${ }^{1}$ and Leila Alibakhshi1, ${ }^{, *}$ \\ ${ }^{1}$ Department of Radiology, School of Dentistry, Shahid Beheshti University of Medical Sciences, Tehran, Iran \\ ${ }^{2}$ Dental Research Center, Research Institute of Dental Sciences, Shahid Beheshti University of Medical Sciences, Tehran, Iran \\ ${ }^{3}$ Rajaie Cardiovascular Medical and Research Center, Iran University of Medical Sciences, Tehran, Iran \\ "Corresponding author: Leila Alibakhshi, Department of Radiology, School of Dentistry, Shahid Beheshti University of Medical Sciences, Tehran, Iran. Tel: +98-2122907040, Fax: \\ +98-2188804037, E-mail: Alibakhshi_l@yahoo.com
}

Received 2016 February 20; Revised 2016 July 17; Accepted 2016 July 25.

\begin{abstract}
Background: Detection of foreign bodies (FBs) is challenging. Selection of a fast and affordable imaging modality to locate the FB with minimal patient radiation dose is imperative.

Objectives: This study sought to compare four commonly used imaging modalities namely cone beam computed tomography (CBCT), magnetic resonance imaging (MRI), computed tomography (CT), and ultrasound (US) for detection of FBs in the head and neck region.

Materials and Methods: In this in vitro study, iron, glass, stone, wood, asphalt, and tooth samples measuring $0.1 \times 0.5 \times 0.5 \mathrm{~cm}$ were placed in the tongue muscle, soft tissue-bone interface and nasal cavity in a fresh sheep's head and subjected to MRI, US, CT and CBCT. A total of 20 images were captured by each imaging system from the six materials in the afore-mentioned locations. The images were observed by an expert oral and maxillofacial radiologist and a general radiologist. To assess reliability, 20 images were randomly observed by the observers in two separate sessions. The images were classified into three groups of good visibility, bad visibility and invisible. The data were analyzed using SPSS version 18, Wilcoxon Signed Rank, Pearson chi square, and Fisher's exact tests.

Results: All FBs in the tongue and at the soft tissue-bone interface had good visibility on US ( $\mathrm{P}=1.00)$. Also, CBCT and CT had significantly different performance regarding FB detection $(\mathrm{P}<0.001)$. All wooden samples in the nasal cavity were invisible on CT scans; while, only $20 \%$ of them were invisible on CBCT scans. MRI showed significant differences for detection of FBs in the three locations $(\mathrm{P}<0.001)$. MRI could not locate iron samples due to severe artifacts and only showed their presence (bad visibility) but other FBs except for wood and tooth in the nasal cavity (100\% invisible) had good visibility on MRI.

Conclusions: Ultrasound is recommended as the first choice when FB is located within the superficial soft tissues with no bone around it. In case of penetration of FB into deeper tissues or beneath bone, CT or CBCT are recommended. Otherwise, considering lower dose, CBCT is preferred over CT. We can use MRI if the FB is not ferromagnetic. However, CT is the first choice in emergency situations because of higher sensitivity.
\end{abstract}

Keywords: Cone Beam Computed Tomography, Foreign Body, Computed Tomography, Foreign Body, Ultrasound

\section{Background}

Foreign body (FB) refers to any object with extrinsic origin that enters into the body. Even the most conservative individuals may experience incidents such as falls, cuts, abrasion, scratches, burns or wounds (1).

Foreign bodies may enter into the body via different routes. They may be swallowed, entered into the body cavities or penetrate the tissue traumatically or via iatrogenic injuries. Motor vehicle accidents and gunshots are among the common causes of traumatic FB injuries (2).
Children, mentally retarded adults, individuals with a recent history of trauma, patients undergoing surgical operation or implantation, magicians, alcoholics, substance abusers, culprits, terrorist attack victims and military personnel are more prone to FB injuries (2).

In the head and neck region, FB injuries often occur due to traffic accidents, explosions, gunshot wounds or maxillofacial therapeutic interventions, and account for $3.8 \%$ of all pathologies in this region (3).

Depending on the type of trauma, the composition, type and location of FB may vary. Wooden sticks in the eyes, 
impression materials in the maxillary sinuses or tooth parts in the eyeball are not uncommon $(4,5)$. In the jawbones, FBs often include amalgam residues or endodontic instruments. Commonly found FBs in the soft tissues of the head and neck region include wooden sticks, pieces of glass, metal objects, stone particles or sands (6).

Complications associated with FB injuries include pain, discomfort, swelling, tenderness, cellulitis, abscess, migration of FB to distant areas and potential injury to the vessels or nerves (2). Infection, inflammation and pain are among the potential complications of FB injuries as well. Inflammatory reactions and granuloma formation may impair wound healing. In addition, FBs can cause serious complications such as intracranial abscess. To prevent complications, FBs must be located and removed as soon as possible $(6,7)$. Superficial FBs are often easily extractable, but FBs that have penetrated deep are hard to remove. Determination of the proximity of FBs to critical organs is important to find out the risks of FB extraction surgery(8). Detection and localization of FBs are done by taking a precise history, clinical examination and facial imaging (3).

Several imaging modalities such as conventional (twodimensional, 2D) radiography, CT, CBCT, MRI and US have been used for detection of FBs (6). Conventional radiography is the primary imaging modality for detection of FBs; however, superimposition of tissues in the path of $\mathrm{X}$ ray beam is the main drawback of $2 \mathrm{D}$ imaging (9-11). Nonradiopaque objects cannot be identified by this modality. Thus, the composition of FB determines its visibility on radiographs. Size of FB also plays a role in this respect.

Detection and localization of FBs in the head and neck region are of utmost importance. Since advanced imaging can facilitate the detection of FBs compared to conventional radiography, diagnostic ability of different imaging modalities for detection of FBs must be compared (12). We decided to undertake this study due to incoherent results of previous studies.

\section{Objectives}

This study sought to compare the ability of four commonly used imaging modalities for detection of FBs made of six materials. The effect of location of FB and the environment in which it is located (namely air, soft tissue and proximity to bone) on its visibility was evaluated as well.

\section{Materials and Methods}

In this in vitro study, iron, glass, stone, wood, asphalt, and tooth samples measuring $0.1 \times 0.5 \times 0.5 \mathrm{~cm}$ were implanted as FBs in a sheep's head. Sample size was calculated as 16 for each material considering $\alpha=0.05, \beta=20 \%, d=0.2$, confidence interval of $95 \%$ and the study power of $80 \%$. To control for possible dropouts, 20 samples were fabricated of each material for each location. Thus, a total of 1440 readings were done (six different materials, three different locations, four imaging modalities and 20 repetitions).

\subsection{Fabrication of Foreign Bodies}

FBs were fabricated of iron, glass, stone, wood, asphalt and tooth (by sectioning), which are among the most commonly found FBs $(0.1 \times 0.5 \times 0.5 \mathrm{~cm})$. The stone sample was a mountain pebble. The asphalt sample was a separated piece of the street asphalt. The tooth sample was fabricated of a tooth extracted due to periodontal disease. The FBs were implanted in three locations in a fresh sheep's head namely in the tongue, nasal cavity and the interface of bone and soft tissue. One sheep head was used for all imaging studies and they were all done during the same day. Each sample was separately placed in the respective locations and subjected to the four imaging modalities.

\subsection{Foreign Body Implantation in the Tongue}

Using a \#15 scalpel, a horizontal incision with $2 \mathrm{~cm}$ depth and 3-4 cm length was made along the tongue muscle and the FB was inserted. Such a lengthy incision was made to enable slight changes in the position of FBs at each implantation.

\subsection{Foreign Body Implantation in the Nasal Cavity}

The FB was tied to a thread $(30 \mathrm{~cm}$, for the purpose of easy retrieval) and placed in the nasal cavity by a hemostat.

\subsection{Foreign Body Implantation at the Interface of Bone and Soft} Tissue

Using a \#15 scalpel, a deep ( $2 \mathrm{~cm}$ ) incision $4-5 \mathrm{~cm}$ in length was made at the vestibular depth of the sheep's mandible to separate the soft tissue from bone. The FB was placed at the interface and the soft tissue was sutured in its baseline position. Such a lengthy incision was made to enable slight changes in the position of FBs at each implantation.

\subsection{Imaging}

Four imaging modalities namely CT, CBCT, MRI and US were carried out in vitro. The CBCT scans were obtained using NewTom VGi (NEWTOM VGi, QR Verona, Italy) with a large $(15 \times 15 \mathrm{~mm})$ field of view (FOV), patient scan mode and high resolution with exposure settings of $110 \mathrm{Kv}$ and $1.43 \mathrm{~mA}$. The scans were viewed using NNT Viewer software. The CT scans were obtained using CT Somatom (Siemens 
Somtom Definition flash, Erlangen, Germany) with number of slices of $2 \times 128,120 \mathrm{kv}, 220 \mathrm{~mA}$ and slice thickness of $0.6 \mathrm{~mm}$. MRI was performed in Shahid Rajaie hospital (Siemens Magnetom Avanto 1.5T) utilizing a head coil. Images were obtained with T1 weighting (TR 600 -700, TE 8 - 9, FOV: 198 x 220, BW150) and T2 weighting (TR 9000 - 10000, TE90 - 100, FOV: 176 x 220, BW190) with slice thickness of 4 $\mathrm{mm}$. US was carried out in Jahad clinic (VOLUSON 730 PRO GE Healthcare Austria) with a linear probe at a frequency of 6 - $12 \mathrm{MHZ}$. Detection of samples was done by a general radiologist.

An expert oral and maxillofacial radiologist (faculty member of Shahid Beheshti University) observed the images, which confirmed the validity of the results.

To assess reliability, 20 images were randomly selected and the observer was requested to observe the images in two separate sessions (the observer was blinded to this process). The results of the two sessions were compared and were found to be similar, which confirmed the reliability of observations. A general radiologist (also a faculty member) was requested to observe the CT, MRI and US images as well. The results of all observations were recorded in code sheets. Based on the visibility of FBs on each image, a qualitative numerical score was allocated to it and it was categorized as good visibility, bad visibility or invisible. The definitions for these states were as follows:

Good visibility: The FB and its details were clearly visible. The borders of the FB were clearly visible as well.

Bad visibility: No details could be seen. The outline of the FB was not clearly visible.

Invisible: The foreign body was not visible at all.

\subsection{Statistical Analysis}

The collected data were subjected to SPSS version 18 (SPSS Inc., Chicago, Ill, USA) and statistically analyzed using Wilcoxon Signed Rank test, Pearson chi square test and Fisher's exact test. Type one error was considered as 0.05 and $\mathrm{P}<0.05$ was considered statistically significant.

\section{Results}

\subsection{Iron FB in the Tongue}

All 20 iron FBs placed in the tongue had bad visibility on CBCT scans and MRI. Wilcoxon Signed Rank test revealed no significant difference in this respect $(\mathrm{P}=1.00)$. Comparison of CBCT and MRI and also CBCT and CT yielded the same results. However, the 20 iron samples had good visibility on US. Thus, US had significant differences in this respect with MRI, CT and CBCT $(\mathrm{P}<0.001)$ (Figures 1 - 4).

\subsection{Glass FB in the Tongue}

Of 20 glass FBs in the tongue, 16 had good and four had bad visibility on MRI; whereas, CBCT, US and CT well visualized all 20 samples (good visibility). The difference in this regard between MRI and each of the CBCT, US, and CT modalities was significant (Wilcoxon Signed Rank test, $\mathrm{P}=$ 0.046). However, US and CBCT, US and CT, and CT and CBCT yielded the same results and well visualized all 20 samples (good visibility, $\mathrm{P}=1.000$ ) (Figures 1 - 4).

\subsection{Stone FB in the Tongue}

Wilcoxon Signed Rank test showed that MRI had a significant difference with US and CT in this respect since all 20 samples had bad visibility on MRI and good visibility on CT and US ( $\mathrm{P}=1.000)$. Of 20 samples, 16 had good and four had bad visibility on CBCT. Thus, СBCT had significant differences with US and CT in this respect $(\mathrm{P}=0.046)$. Also, CBCT had a significant difference with MRI $(\mathrm{P}<0.001)$ (Figures 1 - 4).

\subsection{Wooden FB in the Tongue}

Wilcoxon Signed Rank test showed that CT and CBCT were similar in this respect and all 20 wooden samples were invisible on CT and CBCT scans $(\mathrm{P}=1.00)$. Ten samples had good and 10 had bad visibility on MRI. Thus, MRI had significant differences with $\mathrm{CT}$ and $\mathrm{CBCT}(\mathrm{P}<0.001)$ in this respect; whereas, US had significant differences with CT and CBCT because all 20 samples had good visibility on US while they were invisible on CT and CBCT scans $(\mathrm{P}<0.001)$ (Figures 1-4).

\subsection{Asphalt FB in the Tongue}

Wilcoxon Signed Rank test showed that CBCT and US were similar and all 20 samples had good visibility on CBCT scans and US $(\mathrm{P}=0.001)$. $\mathrm{CBCT}$ and MRI yielded totally different results since all samples had good visibility on CBCT while they all had bad visibility on MRI. This difference was statistically significant $(\mathrm{P}<0.001)$. US and MRI were also different since all 20 samples had good and one sample had bad visibility on US. Thus, US had significant differences with MRI since all 20 samples had bad visibility on MRI ( $\mathrm{P}<0.001)$. One sample had bad and the rest had good visibility on CT, while all 20 samples had good visibility on CBCT scans, but this difference was not significant ( $P$ $<0.317$ ). The same results were obtained for CT and US (Figures 1 - 4). 

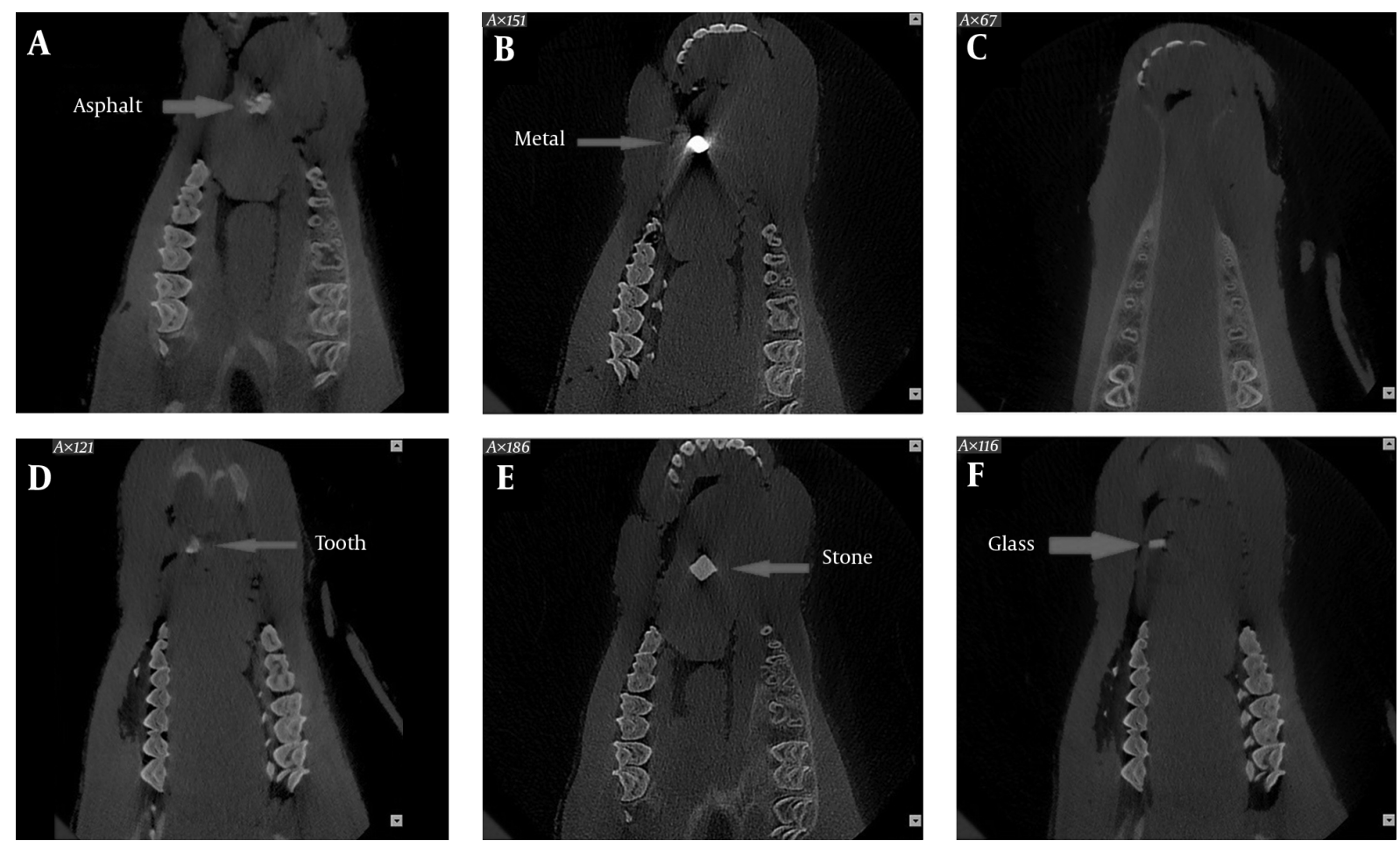

Figure 1. Cone beam computed tomography (CBCT) scans of foreign bodies in the tongue. A, Asphalt; B, Metal; C, Wood; D, Tooth; E,Stone; F, Glass
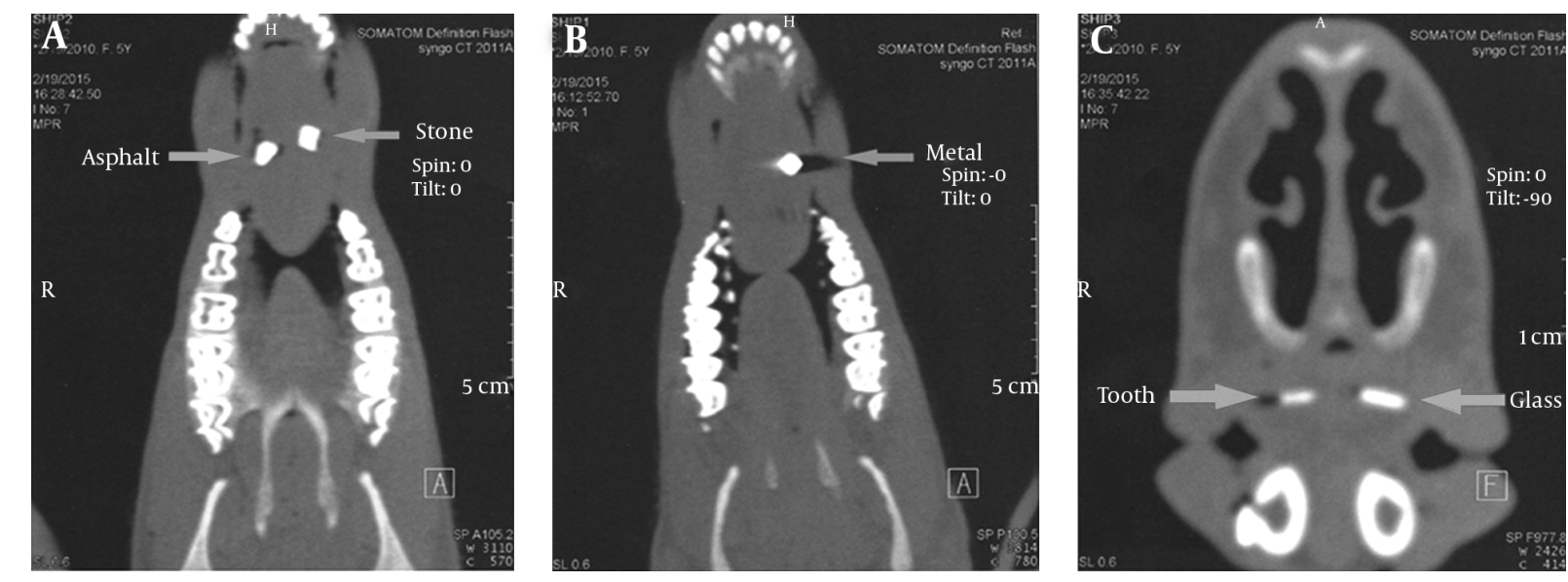

Figure 2. CT scans of the foreign bodies in the tongue. A, Asphalt and stone; B, Wood and metal; C, Tooth and glass

\subsection{Tooth FB in the Tongue}

Wilcoxon Signed Rank test showed that CBCT was similar to US and CT for this purpose since all 20 samples had good visibility on CBCT $(\mathrm{P}=1.000)$. Nine samples had good and 11 samples had bad visibility on MRI and therefore, it had significant differences with CBCT, CT and US, which visualized all 20 samples with good visibility $(\mathrm{P}<0.001)$ (Fig- ures 1 - 4).

\subsection{Iron FB in the Nose}

Wilcoxon Signed Rank test showed no significant difference between CBCT and MRI or CT and all three modalities visualized 20 iron samples with bad visibility $(\mathrm{P}<$ 0.001). Comparison of US with the other three modalities 

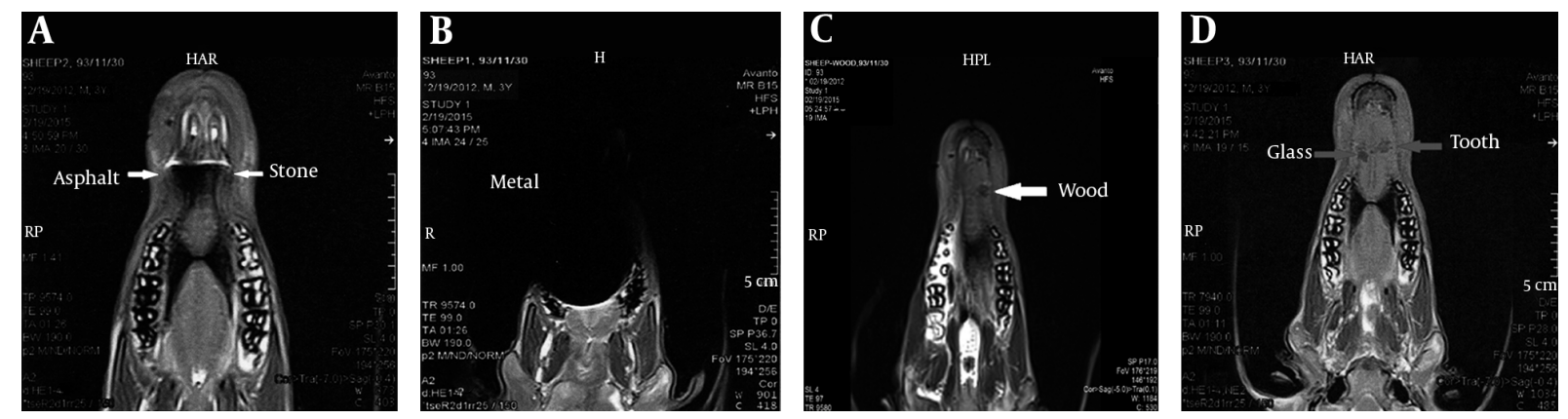

Figure 3. MRI of the foreign bodies in the tongue. A, Asphalt and stone; B, Metal; C, Wood; D, Glass and tooth
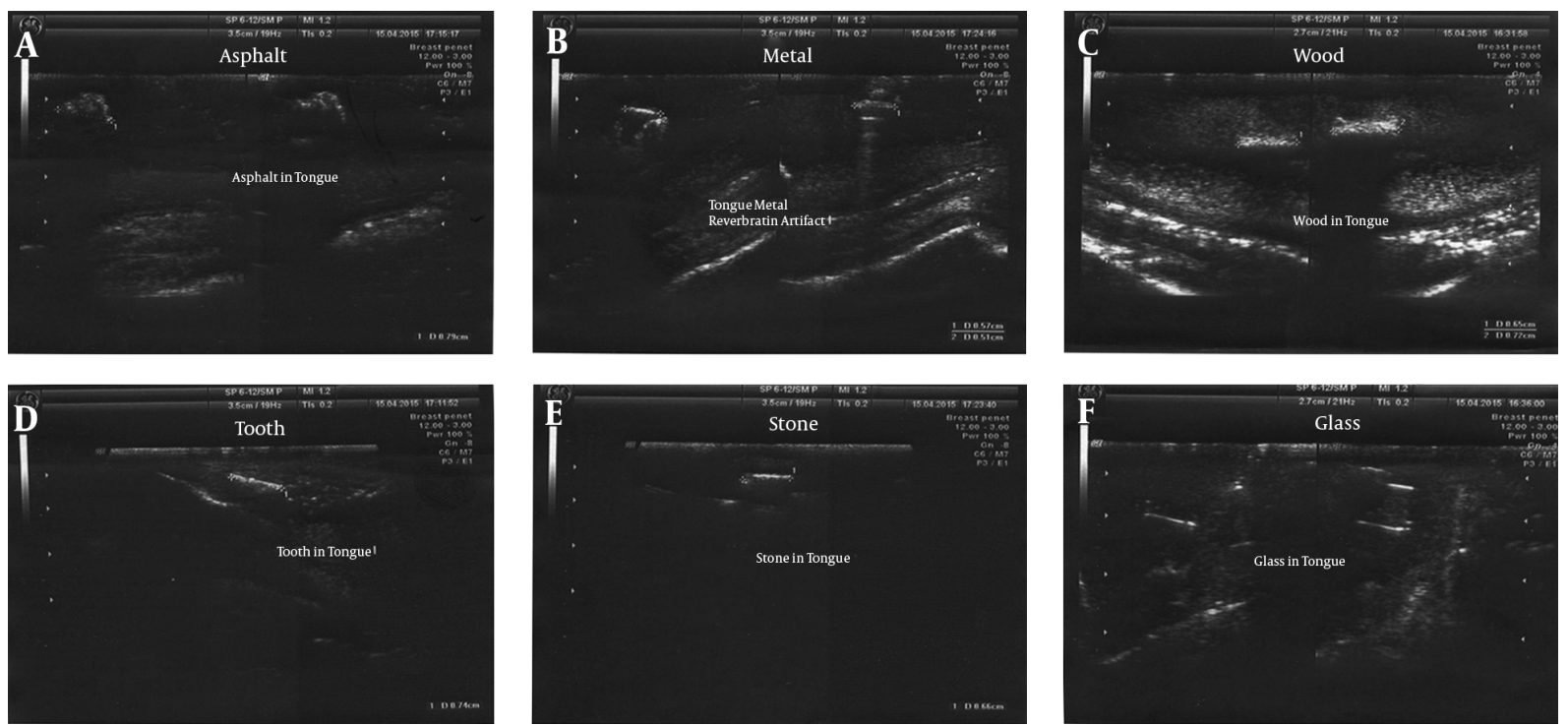

Figure 4. Ultrasound of the foreign bodies in the tongue. A, Asphalt; B, Metal; C, Wood; D, Tooth; E, Stone; F, Glass

yielded significant differences since all 20 were invisible on US while they had bad visibility on CT, MRI and CBCT $(\mathrm{P}<$ 0.001) (Figures $5-8$ ).

\subsection{Glass FB in the Nose}

Wilcoxon Signed Rank test showed no significant difference between CBCT and MRI. CBCT visualized 18 samples with good and two with bad visibility. Seventeen samples had good and three had bad visibility on MRI $(\mathrm{P}=0.655)$. All 20 samples were invisible on US and thus, US had a significant difference in this respect with CT, CBCT and MRI. All 20 had good visibility on CT; 18 had good and two had bad visibility on CBCT scans; 17 samples had good and three had bad visibility on MRI $(\mathrm{P}=0.083)$; $\mathrm{CBCT}$ and $\mathrm{CT}$ were not significantly different $(\mathrm{P}=0.157)$ (Figures 5 - 8).
4.9. Stone FB in the Nose

All 20 samples had bad visibility on MRI; all 20 were invisible on US and this difference was significant $(\mathrm{P}<0.001)$. Comparison of CBCT and MRI revealed a significant difference since 13 had good and seven had bad visibility on CBCT scans ( $\mathrm{P}<0.001) ; 19$ had good and one sample had bad visibility on CT scans and all 20 had bad visibility on MRI; the difference in this regard was significant $(\mathrm{P}<0.001)$. Thirteen samples had good and seven had bad visibility on CBCT scans and the difference with US was significant $(\mathrm{P}<$ 0.001 ) since all 20 were invisible on US. Also, CT had a significant difference with CBCT since 13 had good and one had bad visibility on $\mathrm{CT}(\mathrm{P}=0.034)$. All 20 were invisible on US, which was significantly different from CT since 19 had good and one had bad visibility on $\mathrm{CT}(\mathrm{P}<0.001)$ (Figures 5 - 8). 

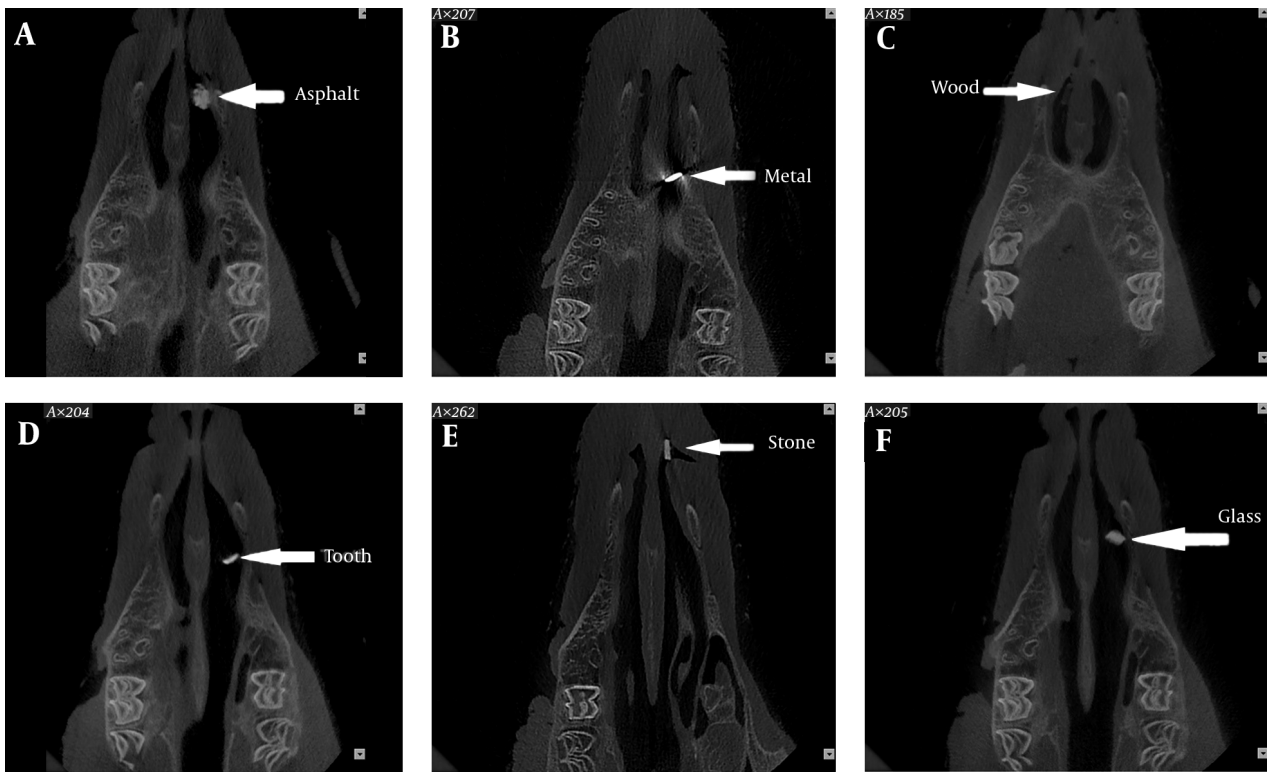

Figure 5. Cone beam computed tomography (CBCT) scans of the foreign bodies in the nose. A, Asphalt; B, Metal; C, Wood; D, Tooth; E, Stone; F, Glass
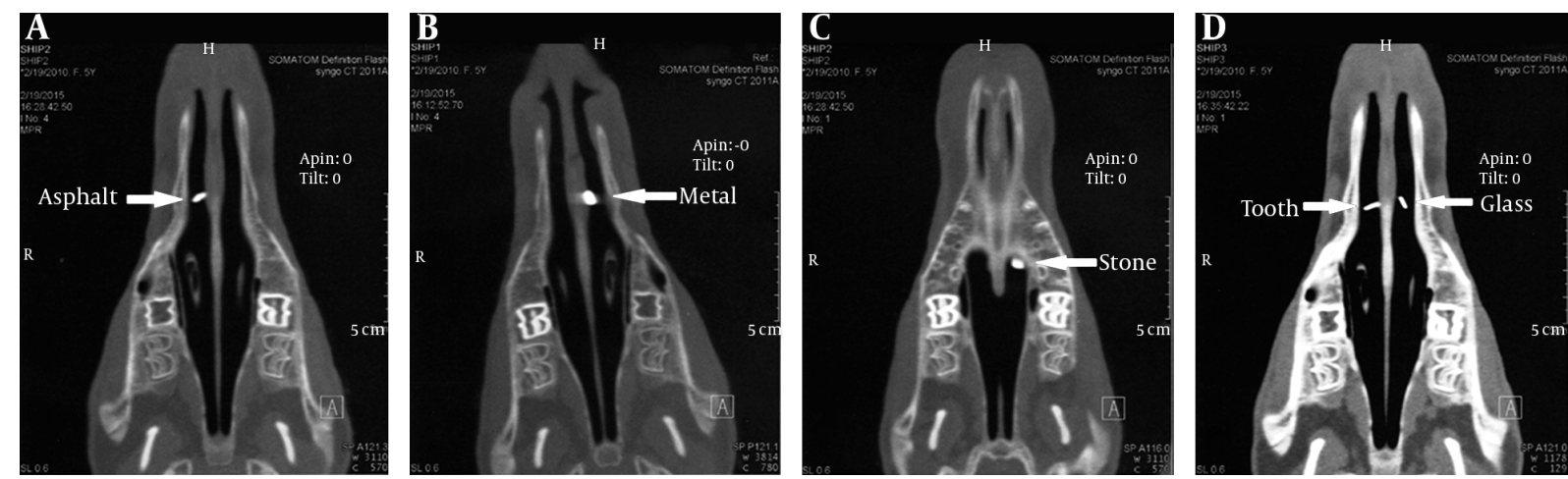

Figure 6. CT scans of the foreign bodies in the nose. A, Asphalt; B, Wood and metal; C, Stone; D, Tooth and glass

\subsection{Wooden FB in the Nose}

Based on Wilcoxon Signed Rank test, MRI was similar to US and CT. All 20 samples were invisible on MRI, US and CT $(P=1.000)$. Sixteen samples had bad visibility on CBCT and four were invisible on CBCT. The difference of CBCT with the other three was statistically significant in this regard $(\mathrm{P}<$ 0.001) (Figures 5 - 8).

\subsection{Asphalt FB in the Nose}

Based on Wilcoxon Signed Rank test, all 20 samples were invisible on US; US had a significant difference with CT and CBCT. All 20 samples had good visibility on CT and 18 had good and two had bad visibility on CBCT; 18 had bad and two had good visibility on MRI $(\mathrm{P}<0.001)$; the difference in this regard was significant as well $(\mathrm{P}<0.001)$. On the other hand, CT and CBCT were not significantly different since all 20 samples had good visibility on CT and two had bad and 18 had good visibility on CBCT scans $(\mathrm{P}<0.157)$. The difference between MRI and CT was significant since all 20 samples had good visibility on CT. Eighteen had bad visibility and two were invisible on MRI $(\mathrm{P}<0.001)$ (Figures 5 $-8)$.

\subsection{Tooth FB in the Nose}

Based on Wilcoxon Signed Rank test, the results of CT and CBCT were similar. All 20 samples had good visibility 

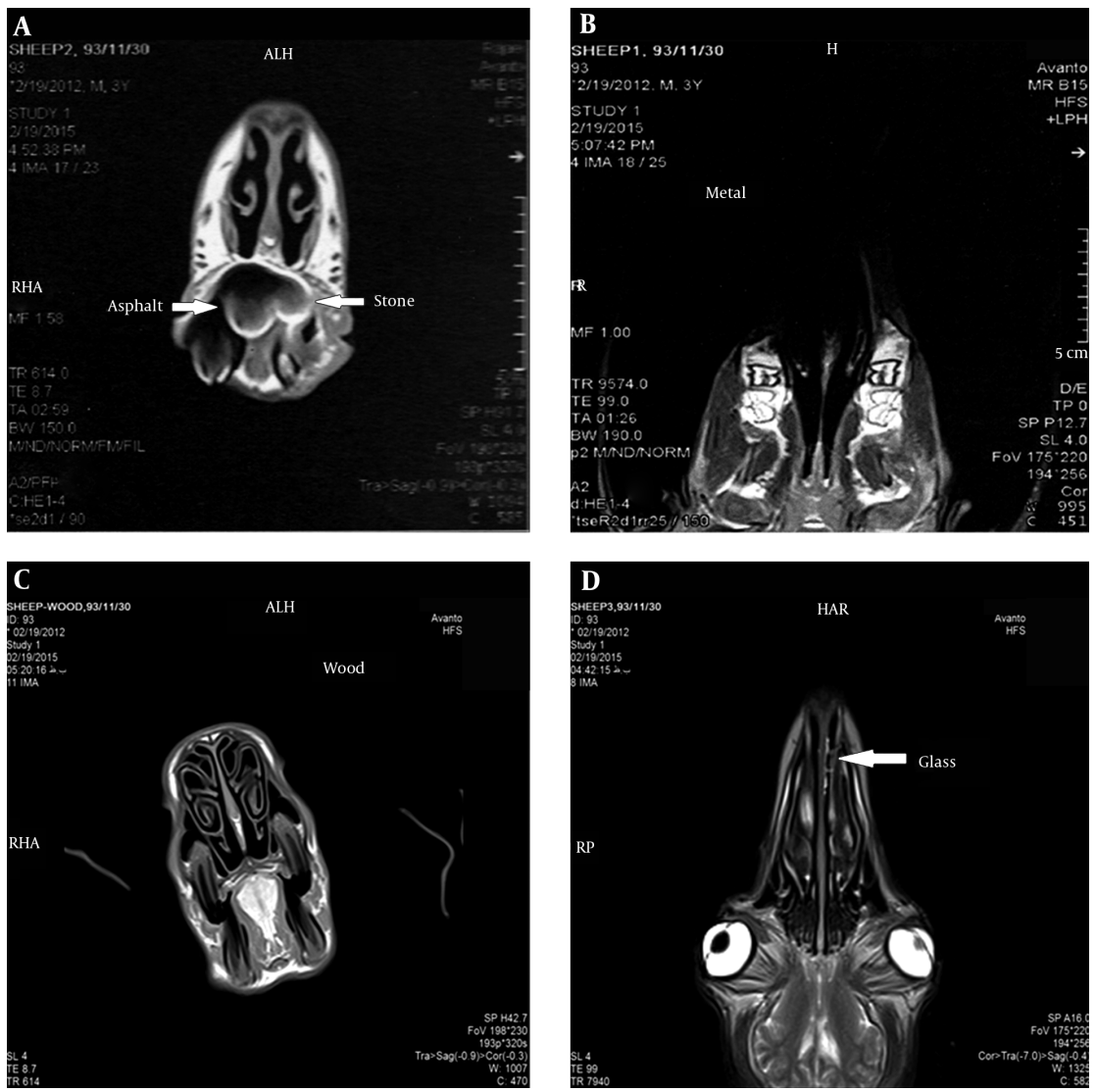

Figure 7. MRI of the foreign bodies in the nose. A, Asphalt and stone; B, Metal; C, Wood; D, Glass and tooth

on CT and CBCT scans $(\mathrm{P}=1.000)$. Also, MRI and US were similar since all 20 samples were invisible on MRI and US (P =

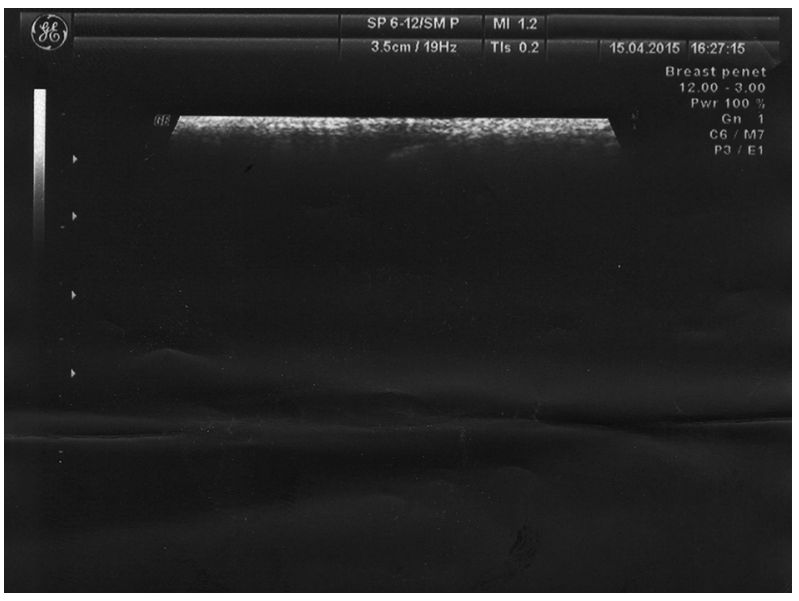

Figure 8. Ultrasound of the foreign bodies in the nose
1.000). Moreover, CT had significant differences with MRI and US $(\mathrm{P}<0.001)$ and CBCT had significant differences with US and MRI in this regard $(\mathrm{P}<0.001)$ (Figures 5 - 8).

\subsection{Iron FB at the Bone-Soft Tissue Interface}

Based on Wilcoxon Signed Rank test, all 20 samples had good visibility on US. All 20 samples had bad visibility on CT, CBCT and MRI; the difference of US with CT, CBCT and MRI was significant $(\mathrm{P}<0.001)$. All 20 samples had bad visibility on CT, CBCT and MRI. Pairwise comparison of the latter three revealed no significant difference $(\mathrm{P}=1.000)$ (Figures 9 -12).

\subsection{Glass FB at the Bone-Soft Tissue Interface}

All 20 samples had good visibility on US; 18 had good and two had bad visibility on MRI; the difference between US and MRI in this respect was not significant $(\mathrm{P}=0.157)$. Nineteen had good and 1 had bad visibility on MRI; the difference of MRI and CT was not significant either $(\mathrm{P}=0.564)$; MRI and CBCT were not significantly different either $(\mathrm{P}=$ 0.655 ) since 17 had good and three had bad visibility on 

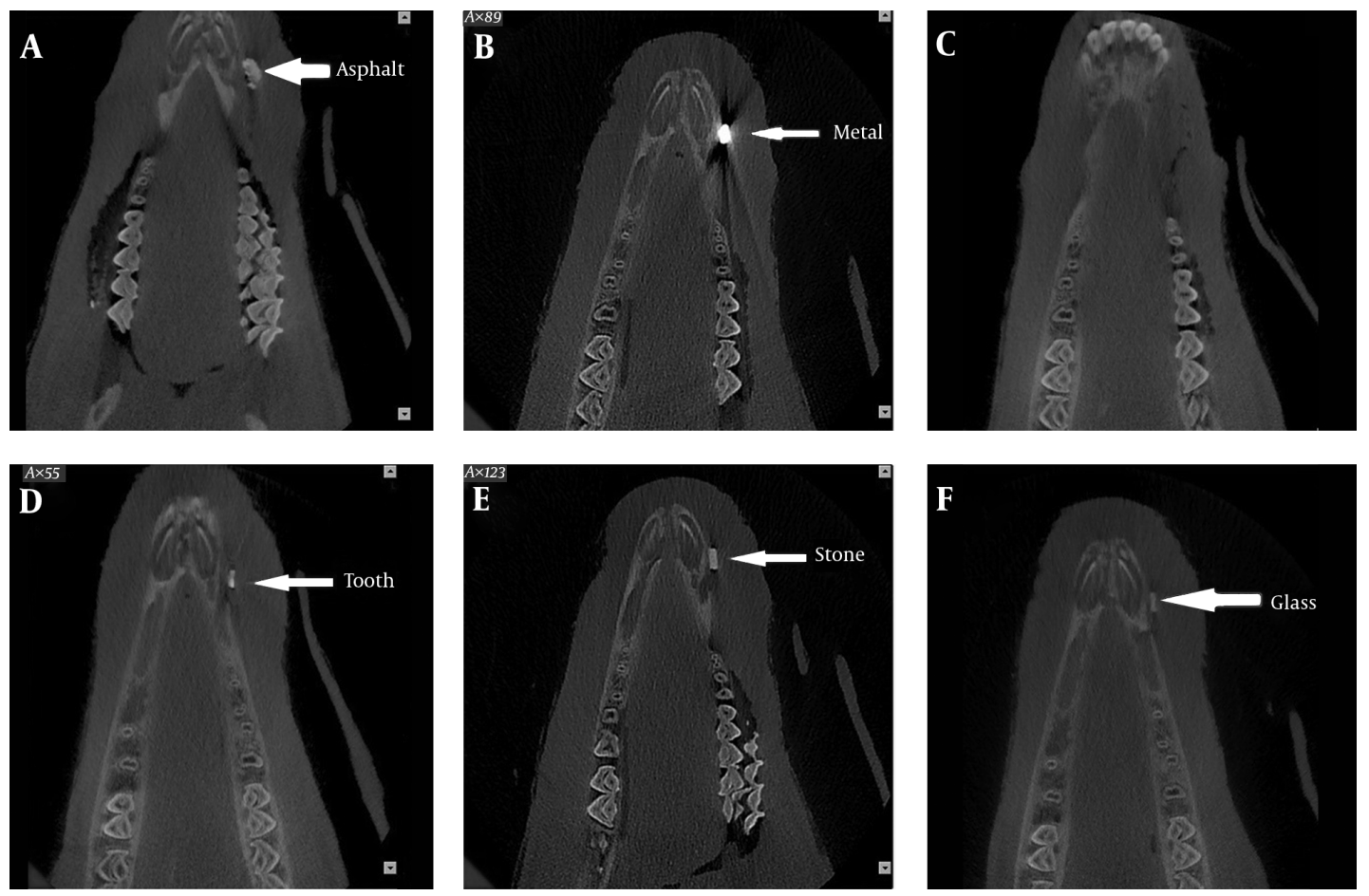

Figure 9. Cone beam computed tomography (CBCT) scans of the foreign bodies in the bone-soft tissue interface. A, Asphalt; B, Metal; C, Wood; D, Tooth; E, Stone; F, Glass

CBCT scans. The US and CT $(\mathrm{P}=0.317)$, US and CBCT $(\mathrm{P}=$ $0.083)$ and $C T$ and $C B C T(P=0.317)$ were not significantly different either (Figures 9 -12).

\subsection{Stone FB at the Bone-Soft Tissue Interface}

All 20 samples had bad visibility on MRI and good visibility on US; the difference between the two was significant $(\mathrm{P}<0.001)$. Nineteen samples had good and one had bad visibility on CT and 12 had good and 8 had bad visibility on CBCT; the difference between CT and CBCT was significant $(\mathrm{P}=0.020)$. Comparison of MRI and $\mathrm{CBCT}$ revealed a significant difference as well $(\mathrm{P}=0.01)$. All 20 had bad visibility on MRI and 19 had good and one had bad visibility on CT; the difference between MRI and CT was significant (P $<0.001)$. Comparison of CT and US revealed no significant difference; one sample had bad and 19 had good visibility on CT ( $\mathrm{P}=0.317)$; the difference between CBCT and US was significant as well $(\mathrm{P}=0.005)$ (Figures 9 -12).

\subsection{Wooden FB at the Bone-Soft Tissue Interface}

Based on Wilcoxon Signed Rank test, all 20 samples were invisible on CT and CBCT and these two modalities were the same in this regard $(\mathrm{P}=1.000)$. Twelve samples had good and 8 had bad visibility on MRI, and MRI had significant differences with CT and CBCT $(\mathrm{P}<0.001)$. Nineteen samples had good and one had bad visibility on US; US had significant differences with CT and CBCT $(\mathrm{P}<0.001)$. US had significant differences with MRI as well since 12 had good and eight had bad visibility on MRI $(\mathrm{P}=0.020)$ (Figure 9 -12).

\subsection{Asphalt FB at the Bone-Soft Tissue Interface}

All 20 samples had good visibility on US and CT and thus, US and CT were not different in this regard $(\mathrm{P}=1.00)$. Eleven samples had good and nine had bad visibility on CBCT; US and CT were significantly different $(\mathrm{P}=0.003)$. All 20 had bad visibility on MRI and the difference between MRI and US and CT was significant in this regard (P $<0.001)$. Also, CBCT and MRI were significantly different ( $P$ $=0.001$ ) (Figures $9-12$ ).

\subsection{Tooth FB at the Bone-Soft Tissue Interface}

Based on Wilcoxon Signed Rank test, CBCT and MRI were not significantly different since 13 samples had good and seven had bad visibility on CBCT; 11 had good and nine had bad visibility on MRI $(\mathrm{P}=0.593)$. The difference of MRI with CT and US was significant since all 20 samples had good visibility on US and CT $(\mathrm{P}=0.003)$. Also, CBCT had significant differences with US and CT since 13 had good and seven had bad visibility on CBCT $(\mathrm{P}=0.008)$. Moreover, CT 

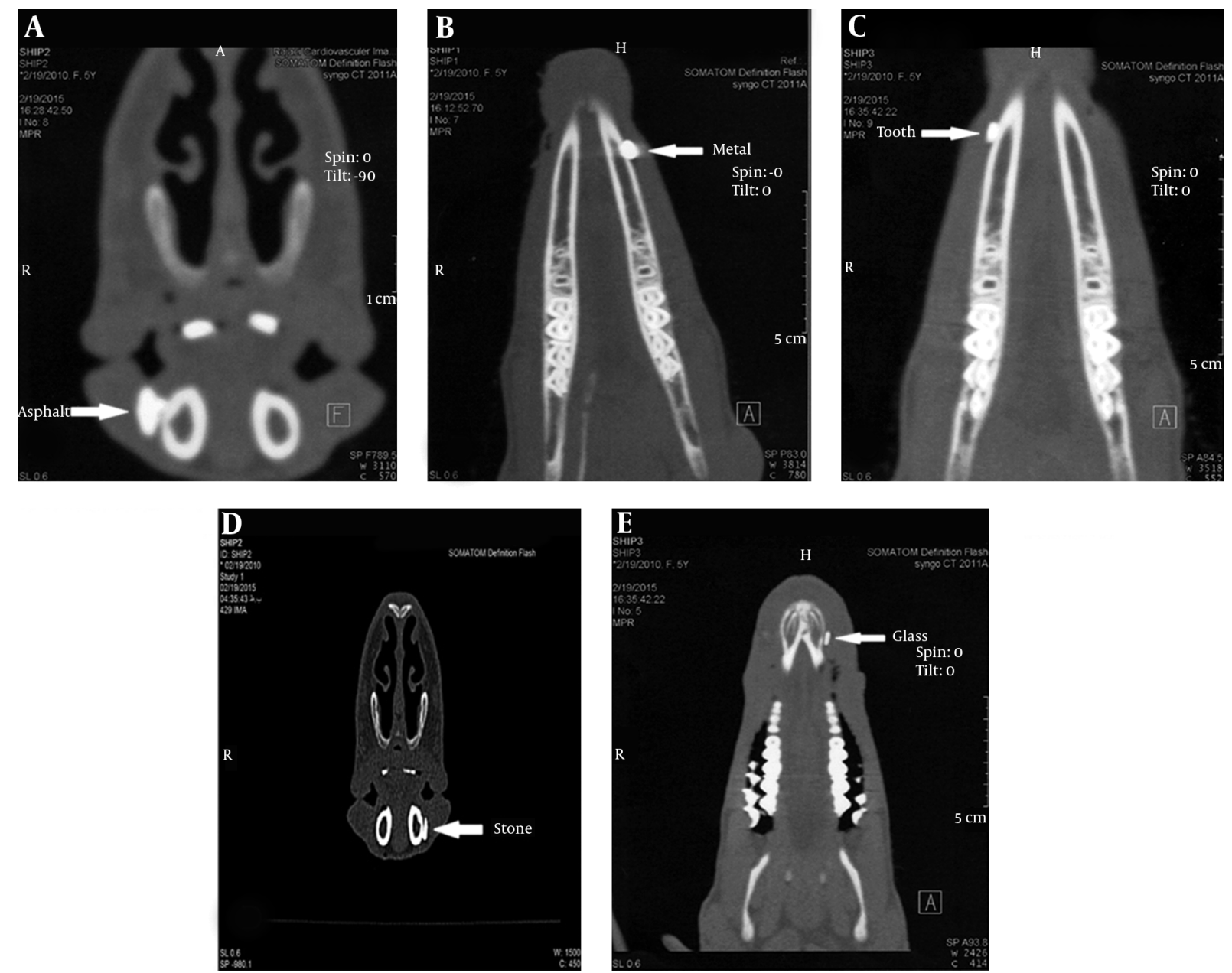

Figure 10. CT scans of the foreign bodies (FB) in the bone-soft tissue interface. A, Asphalt; B, Wood and metal; C, Tooth; D, Stone; E, Glass

and US were similar since all 20 samples had good visibility on CT and US ( $\mathrm{P}=1.000)$ (Figures 9 - 12).

The test results of Fisher's exact test and Pearson ChiSquare are mentioned in Tables 1 - 4. All materials in the nose were invisible and had good visibility in the tongue on US.

\section{Discussion}

Different imaging modalities are used for detection of FBs such as plain radiography, CBCT, MRI, CT, and ultrasound. Plain radiographs can be used to detect FBs and to reveal if they are in a critical location. Although this modality is commonly used, other techniques may be required for exact localization of the FB. The main limitation of plain radiography is that it cannot be used for detection of FBs with low radiopacity.
CT is a standard imaging modality for detection of FBs because the shape and size of objects are accurately reconstructed in this method. CT also determines the exact position of FB and enhances its surgical removal. However, metal artifacts can cause errors in detection of FBs on CT scans. On the other hand, MRI is also used for detection of FBs. If the composition of FB is not known, MRI cannot be used as the first diagnostic modality because artifacts of iron, glass, graphite, asphalt, stone and plastic impede accurate visualization of these objects by MRI. Moreover, MRI can cause displacement of ferromagnetic objects and damage the adjacent tissues. In the head and neck region, CBCT has advantages over CT. СВCT is more affordable and has a lower patient radiation dose than CT (13). US is another imaging modality that can be used to detect FBs. It is easily accessible and available chairside; therefore, it is suitable for use in trauma patients. It is affordable and does not em- 

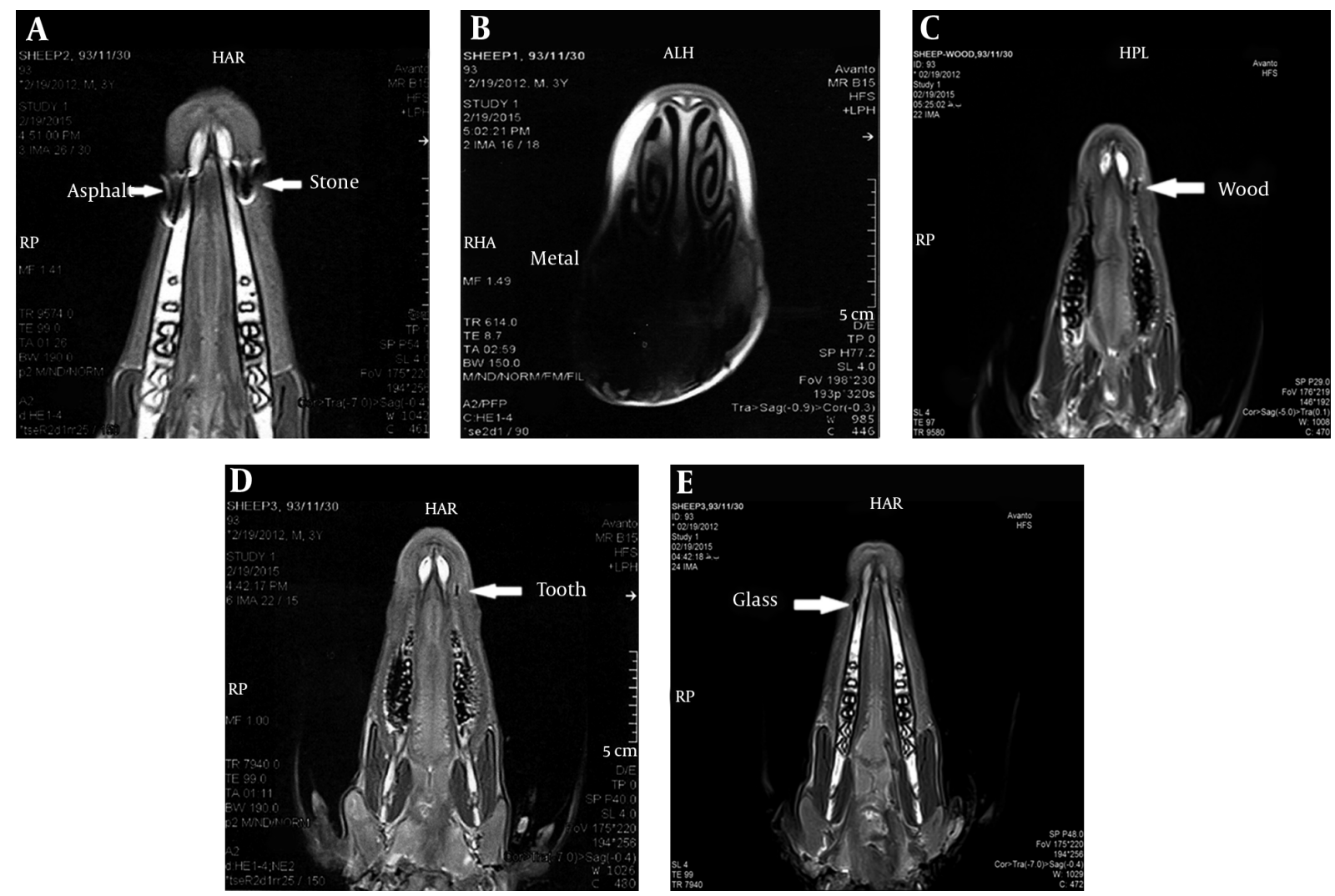

Figure 11. MRI of the foreign bodies in the bone-soft tissue interface. A: Asphalt and stone, B: Metal, C: Wood, D: Tooth, E: Glass
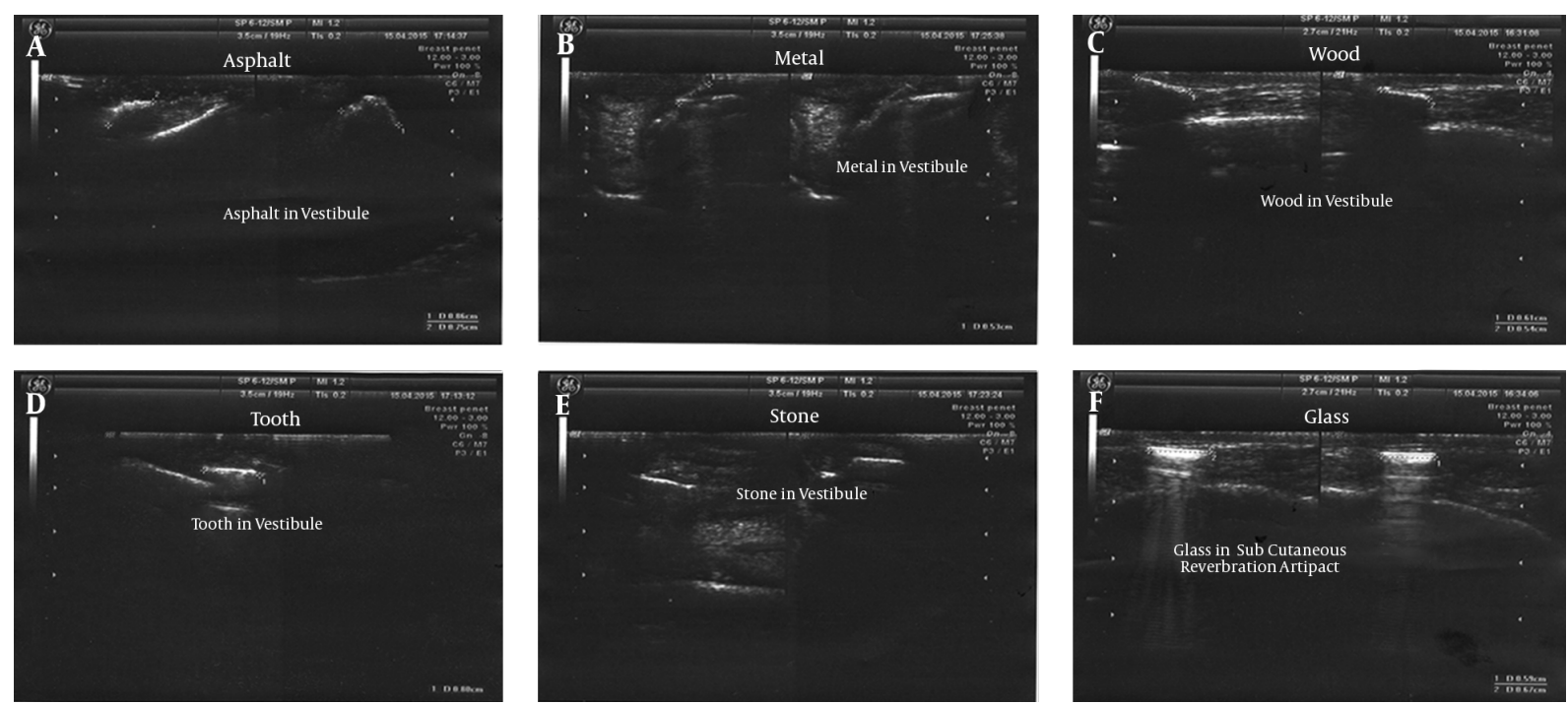

Figure 12. Ultrasound of the foreign bodies in the bone-soft tissue interface. A: Asphalt, B: Metal, C: Wood, D: Tooth, E: Stone, F: Glass

ploy $\mathrm{X}$ ray beams and the obtained images are readily avail- able for evaluation. However, this modality is not suitable 
Table 1. Detection of Different Foreign Bodies by MRI ${ }^{\mathrm{a}, \mathrm{b}}$

\begin{tabular}{|c|c|c|c|c|c|}
\hline Anatomical Location & Foreign Body Type & Good & Bad & Invisible & Total \\
\hline \multirow{7}{*}{ Tongue } & Iron & $0(0.0)$ & $20(100.0)$ & - & $20(100.0)$ \\
\hline & Glass & $16(80.0)$ & $4(20.0)$ & - & $20(100.0)$ \\
\hline & Stone & $0(0.0)$ & $20(100.0)$ & - & $20(100.0)$ \\
\hline & Wood & $10(50.0)$ & $10(50.0)$ & - & $20(100.0)$ \\
\hline & Asphalt & $0(0.0)$ & $20(100.0)$ & - & $20(100.0)$ \\
\hline & Tooth & $9(45.0)$ & $11(55.0)$ & - & $20(100.0)$ \\
\hline & Total & $35(29.2)$ & $85(70.8)$ & - & $120(100.0)$ \\
\hline \multirow{7}{*}{ Nose } & Iron & $0(0.0)$ & $20(100.0)$ & $0(0.0)$ & $20(100.0)$ \\
\hline & Glass & $17(85.0)$ & $3(15.0)$ & $0(0.0)$ & $20(100.0)$ \\
\hline & Stone & $0(0.0)$ & $20(100.0)$ & $0(0.0)$ & $20(100.0)$ \\
\hline & Wood & $0(0.0)$ & $0(0.0)$ & $20(100.0)$ & $20(100.0)$ \\
\hline & Asphalt & $0(0.0)$ & $18(90.0)$ & $2(10.0)$ & $20(100.0)$ \\
\hline & Tooth & $0(0.0)$ & $0(0.0)$ & $20(100.0)$ & $20(100.0)$ \\
\hline & Total & $17(14.2)$ & $61(50.8)$ & $42(35.0)$ & $120(100.0)$ \\
\hline \multirow{7}{*}{ Bone-Soft Tissue Interface } & Iron & $0(0.0)$ & $20(100.0)$ & - & $20(100.0)$ \\
\hline & Glass & $18(90.0)$ & $2(10.0)$ & - & $20(100.0)$ \\
\hline & Stone & $0(0.0)$ & $20(100.0)$ & - & $20(100.0)$ \\
\hline & Wood & $12(60.0)$ & $8(40.0)$ & - & $20(100.0)$ \\
\hline & Asphalt & $0(0.0)$ & $20(100.0)$ & - & $20(100.0)$ \\
\hline & Tooth & $11(55.0)$ & $9(45.0)$ & - & $20(100.0)$ \\
\hline & Total & $41(34.2)$ & $79(65.8)$ & - & $120(100.0)$ \\
\hline
\end{tabular}

${ }^{\mathrm{a}} \mathrm{P}<0.001$

${ }^{\mathrm{b}}$ Values are expressed as No. (\%).

for detection of objects in deep tissues or air filled cavities (14).

The current study showed that CT was efficient for detection of glass, iron, stone, asphalt and tooth but not for wood (low radiopacity). In other words, materials with high radiopacity are detectable on CT scans. However, metal objects cause artifacts and interfere with accurate localization of FBs. In such cases, only presence or absence of FB can be confirmed on CT scan. According to the results of this study, CT had higher sensitivity than other modalities evaluated in the current study. Also, CT can well reveal the outline and accurate size of FBs. The current study results showed that the environment in which the FB is located had no significant effect on its visibility on CT scans. In other words, the diagnostic accuracy of this modality was not affected by the environment in which the FB was located.

In the current study, CBCT and CT yielded similar results. CBCT detected glass, iron, stone, asphalt, and tooth in the three environments studied although metal caused significant artifacts. The visibility of wood in the tongue and at the bone-soft tissue interface on CBCT scans was similar to that on CT scans. In the nose (air-filled cavity), wood often had bad visibility on CBCT scans, while it was not visible at all on CT scans. Wood had a significantly lower density than other materials tested in the current study. It had a density close to that of the adjacent soft tissue. This explains its invisibility on some scans because close density of wood and soft tissue can result in masking of wood on CBCT scans when it is located adjacent to soft tissue.

In 2010, Aras et al. showed that wood adjacent to bone was invisible. It was relatively visible (bad visibility) in an air-filled cavity and within a muscle on CT scans. Relative visibility in their study was defined as invisibility of details, inadequate visualization and impossible precise localization (6). The size of FBs used in their study $(1 \times 1 \times 0.1 \mathrm{~cm})$ explains the relative visibility of wood in the air-filled cavity and muscle since the size of the FB affects its visibility. 
Table 2. Detection of Different Foreign Bodies by $\mathrm{CT}^{\mathrm{a}, \mathrm{b}}$

\begin{tabular}{|c|c|c|c|c|c|}
\hline Anatomical Location & Foreign Body Type & Good & Bad & Invisible & Total \\
\hline \multirow{7}{*}{ Tongue } & Iron & $0(0.0)$ & $20(100.0)$ & $0(0.0)$ & $20(100.0)$ \\
\hline & Glass & $20(100.0)$ & $0(0.0)$ & $0(0.0)$ & $20(100.0)$ \\
\hline & Stone & $20(100.0)$ & $0(0.0)$ & $0(0.0)$ & $20(100.0)$ \\
\hline & Wood & $0(0.0)$ & $0(0.0)$ & $20(100.0)$ & $20(100.0)$ \\
\hline & Asphalt & $19(95.0)$ & $1(5.0)$ & $0(0.0)$ & $20(100.0)$ \\
\hline & Tooth & $20(100.0)$ & $0(0.0)$ & $0(0.0)$ & $20(100.0)$ \\
\hline & Total & $79(65.8)$ & $21(17.5)$ & $20(16.7)$ & $120(100.0)$ \\
\hline \multirow{7}{*}{ Nose } & Iron & $0(0.0)$ & $20(100.0)$ & $0(0.0)$ & $20(100.0)$ \\
\hline & Glass & $20(100.0)$ & $0(0.0)$ & $0(0.0)$ & $20(100.0)$ \\
\hline & Stone & $19(95.0)$ & $1(5.0)$ & $0(0.0)$ & $20(100.0)$ \\
\hline & Wood & $0(0.0)$ & $0(0.0)$ & $20(100.0)$ & $20(100.0)$ \\
\hline & Asphalt & $20(100.0)$ & $0(0.0)$ & $0(0.0)$ & $20(100.0)$ \\
\hline & Tooth & $20(100.0)$ & $0(0.0)$ & $0(0.0)$ & $20(100.0)$ \\
\hline & Total & $79(65.8)$ & $21(17.5)$ & $20(16.7)$ & $120(100.0)$ \\
\hline \multirow{7}{*}{ Bone-Soft Tissue Interface } & Iron & $0(0.0)$ & $20(100.0)$ & $0(0.0)$ & $20(100.0)$ \\
\hline & Glass & $19(95.0)$ & $1(5.0)$ & $0(0.0)$ & $20(100.0)$ \\
\hline & Stone & $19(95.0)$ & $1(5.0)$ & $0(0.0)$ & $20(100.0)$ \\
\hline & Wood & $0(0.0)$ & $0(0.0)$ & $20(100.0)$ & $20(100.0)$ \\
\hline & Asphalt & $20(100.0)$ & $0(0.0)$ & $0(0.0)$ & $20(100.0)$ \\
\hline & Tooth & $20(100.0)$ & $0(0.0)$ & $0(0.0)$ & $20(100.0)$ \\
\hline & Total & $78(65.0)$ & $22(18.3)$ & $20(16.7)$ & $120(100.0)$ \\
\hline
\end{tabular}

${ }^{\mathrm{a}} \mathrm{P}<0.001$

${ }^{\mathrm{b}}$ Values are expressed as No. (\%).

In two studies conducted by Eggers et al. in 2007 (7) and 2005 (15), they evaluated the visibility of FBs of variable sizes and reported results similar to our study.

In 2014, Kaviani et al. evaluated the diagnostic accuracy of CT and CBCT for detection of FBs; namely, metal, tooth, wood, plastic, glass stone, and graphite. They reported that except for wood, all FBs were visible on both CT and CBCT scans (13).

In the current study, the efficacy of MRI for FB detection was also evaluated. Ferromagnetic objects had the potential risk of displacement in the MRI scanner. Also, aside from this problem, iron on T1 and T2 weighted images had high artifacts and a large portion of the sheep's head was dark. Therefore, MRI can only show the presence of FB and cannot be used for its localization. Asphalt and stone were visible in all three locations but due to high artifact (artifact of asphalt was higher than that of stone), only the presence of the FB was confirmed (especially in T1 weighted images) and its localization was not possible. On T2 images, it was the artifact of asphalt and tooth that made them detectable and not the object itself.

Glass on T1 and T2 weighted images was visible as an area of low signal intensity. It had good and sometimes bad visibility when located in the tongue and at the bone-soft tissue interface. Moreover, MRI could not detect tooth in the nasal cavity. Also, wood was visible as an area of low signal intensity on T1 and T2 weighted images. MRI visualized wood in the tongue and at the bone-soft tissue interface and it had good visibility. Wooden samples in the nose were detectable by MRI.

In our study, all FBs in the tongue and at the bone-soft tissue interface had good visibility on US, but none of the FBs in the nose were visible. Iron and glass had reverberation artifact on US. Asphalt and tooth were visualized as non-homogenous (irregular) masses along with a posterior shadow. Wood and stone were visualized as echogenic masses along with a posterior shadow with good visibility. Our study clearly indicated the ability of US in visualizing 
Table 3. Detection of Different Foreign Bodies by Cone Beam Computed Tomography ${ }^{\mathrm{a}, \mathrm{b}}$

\begin{tabular}{|c|c|c|c|c|c|}
\hline Anatomical Location & Foreign Body Type & Good & Bad & Invisible & Total \\
\hline \multirow{7}{*}{ Tongue } & Iron & $0(0.0)$ & $20(100.0)$ & $0(0.0)$ & $20(100.0)$ \\
\hline & Glass & $20(100.0)$ & $0(0.0)$ & $0(0.0)$ & $20(100.0)$ \\
\hline & Stone & $16(80.0)$ & $4(20.0)$ & $0(0.0)$ & $20(100.0)$ \\
\hline & Wood & $0(0.0)$ & $0(0.0)$ & $20(100.0)$ & $20(100.0)$ \\
\hline & Asphalt & $20(100.0)$ & $0(0.0)$ & $0(0.0)$ & $20(100.0)$ \\
\hline & Tooth & $20(100.0)$ & $0(0.0)$ & $0(0.0)$ & $20(100.0)$ \\
\hline & Total & $76(63.3)$ & $24(20.0)$ & $20(16.7)$ & $120(100.0)$ \\
\hline \multirow{7}{*}{ Nose } & Iron & $0(0.0)$ & $20(100.0)$ & $0(0.0)$ & $20(100.0)$ \\
\hline & Glass & $18(90.0)$ & $2(10.0)$ & $0(0.0)$ & $20(100.0)$ \\
\hline & Stone & $13(65.0)$ & $7(35.0)$ & $0(0.0)$ & $20(100.0)$ \\
\hline & Wood & $0(0.0)$ & $16(80.0)$ & $4(20.0)$ & $20(100.0)$ \\
\hline & Asphalt & $18(90.0)$ & $2(10.0)$ & $0(0.0)$ & $20(100.0)$ \\
\hline & Tooth & $20(100.0)$ & $0(0.0)$ & $0(0.0)$ & $20(100.0)$ \\
\hline & Total & $69(57.5)$ & $47(39.2)$ & $4(3.3)$ & $120(100.0)$ \\
\hline \multirow{7}{*}{ Bone-Soft Tissue Interface } & Iron & $0(0.0)$ & $20(100.0)$ & $0(0.0)$ & $20(100.0)$ \\
\hline & Glass & $17(85.0)$ & $3(15.0)$ & $0(0.0)$ & $20(100.0)$ \\
\hline & Stone & $12(60.0)$ & $8(40.0)$ & $0(0.0)$ & $20(100.0)$ \\
\hline & Wood & $0(0.0)$ & $0(0.0)$ & $20(100.0)$ & $20(100.0)$ \\
\hline & Asphalt & $11(55.0)$ & $9(45.0)$ & $0(0.0)$ & $20(100.0)$ \\
\hline & Tooth & $13(65.0)$ & $7(35.0)$ & $0(0.0)$ & $20(100.0)$ \\
\hline & Total & $53(44.2)$ & $47(39.2)$ & $20(16.7)$ & $120(100.0)$ \\
\hline
\end{tabular}

${ }^{\mathrm{a}} \mathrm{P}<0.001$.

${ }^{\mathrm{b}}$ Values are expressed as No. (\%).

Table 4. Detection of Different Foreign Bodies by Ultrasound ${ }^{\mathrm{a}, \mathrm{b}}$

\begin{tabular}{|c|c|c|c|c|c|}
\hline & Foreign Body Type & Good & Bad & Invisible & Total \\
\hline \multirow{7}{*}{ Bone-Soft Tissue Interface } & Iron & $20(100.0)$ & $0(0.0)$ & - & $20(100.0)$ \\
\hline & Glass & $20(100.0)$ & $0(0.0)$ & - & $20(100.0)$ \\
\hline & Stone & $20(100.0)$ & $0(0.0)$ & - & $20(100.0)$ \\
\hline & Wood & $19(95.0)$ & $1(5.0)$ & - & $20(100.0)$ \\
\hline & Asphalt & $20(100.0)$ & $0(0.0)$ & - & $20(100.0)$ \\
\hline & Tooth & $20(100.0)$ & $0(0.0)$ & - & $20(100.0)$ \\
\hline & Total & $119(99.2)$ & $1(0.8)$ & - & $120(100.0)$ \\
\hline
\end{tabular}

${ }^{\mathrm{a}} \mathrm{P}=0.001$

${ }^{\mathrm{b}}$ Values are expressed as No. (\%).

FBs located in superficial tissues and its inability to detect FBs located in deep tissues or beneath bones.

In 1994, Mizel et al. evaluated CT, MRI, and US for detection of wooden FBs. They preferred MRI and US for detection of FBs as their first diagnostic modality (16). In
2008, Ober et al. compared CT, MRI and US for detection of wooden FBs in the canine manus and reported CT as a more accurate modality than MRI and US (17).

In 2009, in an vivo study, Shrestha et al. evaluated 23 patients suspected for FBs in their extremities. US detected 
non-radiopaque FBs in the extremities of 19 patients. The accuracy of US was surgically confirmed (18).

In general, imaging modalities used for detection of FBs have advantages and disadvantages. Factors such as the degree of radiopacity may affect their visibility. Future studies are required to determine the minimum detectable size of different FBs. In clinical settings, factors such as composition of the $\mathrm{FB}$, location, availability of the imaging modality, affordability, and patient radiation dose should be considered in the selection of the imaging modality.

In conclusion, when there is a possibility of $\mathrm{FB}$ in the superficial tissues (muscle, or at the bone soft tissue interface), US is recommended for assessment of presence or absence of the FB. If the FB is located in deep tissues or behind a bone, $\mathrm{CBCT}$ and then $\mathrm{CT}$ are recommended because of the lower patient radiation dose and lower cost. Also, MRI has the advantage of not using radiation beam and it yields more optimal results compared to $\mathrm{CBCT}$ and $\mathrm{CT}$ in detecting FBs with low opacity such as wood. However, if the FB is a ferromagnetic metal, MRI may displace it and cause serious problems for the patient. Thus, MRI is contraindicated in such cases. Otherwise, MRI can replace CBCT and CT. In US, radiopacity of the materials has no effect on their visibility, but CT and CBCT detected high-opacity materials such as metal, glass and asphalt better than low opacity materials such as wood. In addition, in air-filled cavities, CBCT detected wood in most cases. Different locations affected the visibility of FBs in US. FBs in superficial tissues were visible, while they were invisible in deep tissues such as the nasal cavity. Location had no effect on the visibility of FBs in other methods, which may be due to the size of FBs. If the FBs were smaller, they could have been masked in different locations.

According to the results, the sensitivity of $\mathrm{CT}$ was higher than that of other modalities. In emergency situations, a critical decision is important to enhance faster treatment planning. Moreover, all parts of the body must be evaluated in traumatic patients and CT is the best modality for such cases.

\section{Footnotes}

Authors' Contribution: Solmaz Valizadeh and Leila Alibakhshi were responsible for the study concept and design, analysis and interpretation of data, critical revision of the manuscript for important intellectual content, and study supervision; acquisition of data was carried out by Solmaz Valizadeh, Leila Alibakhshi, Hamidreza Pouraliakbar, and Leila Kiani; drafting of the manuscript was done by Leila Alibakhshi. Alireza Akbarzadeh Bagheban performed the statistical analysis; administrative, technical, and material support was achieved by Solmaz Valizadeh, Leila Alibakhshi, Hamidreza Pouraliakbar, Yase Safi , and Leila Kiani.

Financial Disclosure: None declared.

Funding/Support: This study was supported by a financial grant from Shahid Beheshti University of Medical Sciences.

\section{References}

1. Passali D, Gregori D, Lorenzoni G, Cocca S, Loglisci M, Passali FM, et al Foreign body injuries in children: a review. Acta Otorhinolaryngol Ital. 2015;35(4):265-71. [PubMed: 26824213].

2. Hunter TB, Taljanovic MS. Foreign bodies. Radiographics. 2003;23(3):731-57. doi: 10.1148/rg.233025137. [PubMed: 12740473].

3. Oikarinen KS, Nieminen TM, Makarainen H, Pyhtinen J. Visibility of foreign bodies in soft tissue in plain radiographs, computed tomography, magnetic resonance imaging, and ultrasound. An in vitro study. Int J Oral Maxillofac Surg. 1993;22(2):119-24. [PubMed: 8320449].

4. Akhaddar A, Abouchadi A, Jidal M, Gazzaz M, Elmostarchid B, Naama $\mathrm{O}$, et al. Metallic foreign body in the sphenoid sinus after ballistic injury: a case report. J Neuroradiol. 2008;35(2):125-8. doi 10.1016/j.neurad.2007.06.005. [PubMed: 17628677].

5. Dort JC, Robertson D. Nonmetallic foreign bodies of the skull base: a diagnostic challenge. J Otolaryngol. 1995;24(1):69-72. [PubMed: 7769650].

6. Aras MH, Miloglu O, Barutcugil C, Kantarci M, Ozcan E, Harorli A. Comparison of the sensitivity for detecting foreign bodies among conventional plain radiography, computed tomography and ultrasonography. Dentomaxillofac Radiol. 2010;39(2):72-8. doi: 10.1259/dmfr/68589458. [PubMed: 20100917].

7. Eggers G, Welzel T, Mukhamadiev D, Wortche R, Hassfeld S, Muhling J. X-ray-based volumetric imaging of foreign bodies: a comparison of computed tomography and digital volume tomography. J Oral Maxillofac Surg. 2007;65(9):1880-5. doi: 10.1016/j.joms.2006.09.029. [PubMed: 17719420].

8. Fowler TR, Crellin SJ, Greenberg MR. Detecting foreign bodies in a head laceration. Case Rep Emerg Med. 2015;2015:801676. doi: 10.1155/2015/801676. [PubMed: 25802770].

9. Tas S, Top H. Intraorbital wooden foreign body: clinical analysis of 32 cases, a 10-year experience. Ulus Travma Acil Cerrahi Derg. 2014;20(1):515. doi: 10.5505/tjtes.2014.93876. [PubMed: 24639316].

10. Shepherd M, Lee J, McGahon MC. Diagnostic Modalities for the Detection of Soft Tissue Foreign Bodies. Adv Emerg Nurs J. 2007;29(4):297308. doi: 10.1097/01.TME.0000300111.86701.9b.

11. Al-Mujaini A, Al-Senawi R, Ganesh A, Al-Zuhaibi S, Al-Dhuhli H. Intraorbital foreign body: clinical presentation, radiological appearance and management. Sultan Qaboos Univ Med J. 2008;8(1):69-74. [PubMed: 21654960].

12. Roobottom CA, Weston MJ. The detection of foreign bodies in soft tissue-comparison of conventional and digital radiography. Clin Radiol. 1994;49(5):330-2. [PubMed: 8013198].

13. Kaviani F, Javad Rashid R, Shahmoradi Z, Gholamian M. Detection of foreign bodies by spiral computed tomography and cone beam computed tomography in maxillofacial regions. J Dent Res Dent Clin Dent Prospects. 2014;8(3):166-71. doi: 10.5681/joddd.2014.030. [PubMed: 25346836].

14. Davis J, Czerniski B, Au A, Adhikari S, Farrell I, Fields JM. Diagnostic Accuracy of Ultrasonography in Retained Soft Tissue Foreign Bodies: A Systematic Review and Meta-analysis. Acad Emerg Med. 2015;22(7):77787. doi: 10.1111/acem.12714. [PubMed: 26111545]. 
15. Eggers G, Mukhamadiev D, Hassfeld S. Detection of foreign bodies of the head with digital volume tomography. Dentomaxillofac Radiol 2005;34(2):74-9. doi: 10.1259/dmfr/22475468. [PubMed: 15829688].

16. Mizel MS, Steinmetz ND, Trepman E. Detection of wooden foreign bodies in muscle tissue: experimental comparison of computed tomography, magnetic resonance imaging, and ultrasonography. Foot Ankle Int. 1994;15(8):437-43. [PubMed: 7981816].

17. Ober CP, Jones JC, Larson MM, Lanz OI, Werre SR. Comparison of ul- trasound, computed tomography, and magnetic resonance imaging in detection of acute wooden foreign bodies in the canine manus. Vet Radiol Ultrasound. 2008;49(5):411-8. [PubMed: 18833946].

18. Shrestha D, Sharma UK, Mohammad R, Dhoju D. The role of ultrasonography in detection and localization of radiolucent foreign body in soft tissues of extremities. JNMA JNepal Med Assoc. 2009;48(173):5-9. [PubMed: 19529050]. 